\title{
Editorial
}

\section{We all loved Gumby: Examining the pros and cons of DAM flexibility}

\section{Brett Shamosh}

is the Director of Post Production and Media Management for College Sports Television, the first US 24-hour college sports network. As a former producer, shooter and editor, he applies his production knowledge to the pursuit of effective media asset management solutions for sports television. He is working closely with Venaca to achieve a seamless workflow for the ingestion, storage and sharing of CSTV's digital assets. Prior to joining CSTV, he served as a post production supervisor at Oxygen and filled several production roles at NHL Productions. He studied television, radio and film production at the SI Newhouse School of Public Communications, Syracuse University.

He was green. He could walk, jog, run, stand, sit, cover his eyes or throw his hands in the air. And we all loved it. But why did we love it? We loved it because we could make a toy figure do whatever we wanted it to do. Secondly, and more importantly for the purposes of this Editorial, we loved it because whatever we did to it didn't really matter. Gumby served no purpose other than to entertain, and while media asset management (MAM) solutions can sometimes be entertaining, they serve a much more significant purpose.

The field of digital asset management (DAM) is so broad that I must narrow this commentary down to my discipline: broadcasting. In broadcasting, we refer to DAMs as MAMs. This is primarily because we deal with video and audio, known as "media", but also because the word "damn" is used enough during the course of a normal broadcast day to cause confusion.

Many MAM solutions have hit the market over the past five years. Each touts itself as the industry leader, flexible enough to plug and play into your workflow. According to Webster's, there can be only one leader, but most MAM solutions are indeed flexible. But are they too flexible? My mother has lived in New Jersey her entire life. You can pick any two points in the state and she'll get you from A to B using side streets. There's only one catch. She'll give you a choice of at least five different ways to go, leaving you more confused than before you called. I prefer MapQuest, but I still call her anyway because I know she loves to feel helpful.

As broadcasters, our content is only as good as our ability to distribute it. As new means of digital distribution emerge, we must be positioned to efficiently retrieve and repurpose our assets. Almost every MAM solution on the market will allow a broadcaster to do just that-some better than others. But providers have taken extra steps to be part of the projected MAM market share. Ask any MAM vendor a question and you will get the same canned opening to an answer: "We can do that however you'd like." It reminds me of a small family-style Italian restaurant where everything is made to order and you can create your own dish.

Sometimes this is great.

In the hands of the right people, flexible software can be a wonderful thing. Who wouldn't want a custom-tailored application with a user interface (UI) designed just for you? But remember that, unlike Gumby, this stuff matters. The pros are obvious, but the cons are much more transparent. Added flexibility means added labor, added support and added risk. Now's a pretty good time to mention that the MAM provider I currently use has a good grasp on all these issues.

MAM solutions can be as flexible as you'd like them to be. Whether it's your vendor tweaking processes on the back end or a user customizing fields on the front end, changes can be made very quickly. A good rule of thumb in this field is that changes require labor and labor costs money. By that logic, a flexible MAM solution can be very costly.

Changes also require training, support and possibly increased staff. Some MAM solution 
contracts cover this and some don't. You can't really structure a contract to include things you can't predict. So unless Nostradamus is your general counsel, it's worth considering the flexibility of the MAM solution you choose.

A good MAM solution allows for one asset to be viewed and manipulated by many users. What the users do with the asset is up to them. But if the purpose of the system is to increase efficiencies and share assets, it's usually a good idea to keep conventions standard. There are always exceptions to the rule, but changes in workflow and UIs should pass through an administrator. Once again, this is an area that can become extremely costly and cause major headaches without the right people at the helm.

Flexibility is not all bad. It's really nice to set up a UI to reflect the skill set of a specific user. This can prevent problems and increase efficiency. Since I love to play devil's advocate, I will note that someone is administrating these UI setups. But the true benefit of flexibility is that it creates new business. Should you want to distribute your assets in different formats for marketing/promotions purposes, specific tools can be designed to automate these tasks. Tools can be mapped to your fingertips to grab stills for press, create DVDs for clients, or perform quick transcodes for the web.

The above thoughts are offered for your consideration. As one who is in the trenches on a daily basis, I appreciate the flexibility of my MAM solution. However, I am the only one who knows how flexible our system really is. (I hope my management doesn't read this Editorial or I'm going to get a lot of questions!) My intention was merely to strike a nerve and get readers thinking about their MAM flexibility as more than just an advantage. If I failed, I hope I at least reminded you how much you loved Gumby. 